\title{
REVIEWS
}

\section{ESSENTIALS OF INDUSTRIAL HEALTH}

By E. O. Sappington, M.D., Dr.P.H.

(Lippincott Company, Philadelphia and London. 1943. Pp. 626. Illustrated. 42s.)

Very few books on industrial medicine have been published in this country, so this new volume will prove useful as a book of reference for the established medical officer and a helpful guide to those new to industry. While the subject matter is culled from American experience the figures quoted and the views expressed may stimulate industrial medical officers in this country to investigate many of their own problems in a similar manner to that adopted in the U.S.A. Although we were pioneers in the improvement of industrial working conditions, and much American legislation has been based on the experience of our Factory Department descriptions of the type of industrial medical service of many American companies suggest that on some points they have outstripped us. The author takes the realistic view that industrial health service pays handsomely and gives figures to support this.

The book is divided into three main parts. Part one, on industrial health administration, covers the history of industrial medicine, occupational morbidity and mortality. The scope and objectives of industrial health, the type of knowledge required by the industrial medical officer, and the organization of medical services for small and large factories are given in detail. Part two, on industrial hygiene and toxicology, is valuable in that it classifies the various types of industrial health exposure, giving lists of materials and circumstances likely to affect health with a description of the clinical picture and the trades in which such dangers are encountered. The way to survey plants with simple methods of sampling and analysis should prove helpful in controlling and maintaining control of working conditions. Planned sanitation and hygiene for workers including co-ordination of industrial and community health services are described in detail. Part three deals with industrial medicine and traumatic surgery and covers methods of co-ordinating the worker's physical and mental make-up with the job he has to do. Causes of industrial accidents and occupational disease are estimated and their control and treatment described. The importance of prevention is the keynote of this book. The author at every stage stresses the value of keeping adequate records and, what is far more important, the use to which such records can be put.

W. E. C.

\section{A GUIDE FOR THE TUBERCULOUS PATIENT} By G. S. Erwin, M.D.

(William Heinemann, London. 1944. Pp. 112. 3s. 6d.)

Dr. Erwin has fulfilled a great need by supplying this useful book for the tuberculous patient. It explains in simple language the nature of the disease and the conditions which are necessary for its successful treatment. To do this is a most important part of the treatment of any chronic disease which does not completely incapacitate the patient. It is specially important at the present time when, rightly, attention is focussed on the employment of the disabled. Pulmonary tuberculosis incapacitates more people in the prime of their working life than any other disease. On choice of work, however, Dr. Erwin states that 'individual advice should be sought from the sanatorium medical officer.' These doctors can certainly advise on the patient's response to work and exercise but probably have had little experience of work in most industries. It is certain that consultation between the industrial medical officer and the sanatorium medical officer would result in better advice than could be given by either alone. On the subject of food in the sanatorium, Dr. Erwin implies that there is often complaint and suggests that the patient is at fault. Food can, and should be, served well and attractively to the sick, but one fears that in many public institutions this is not done. Surely, therefore, rather than condemn the patient it would be better to stimulate a movement to provide appetizing food in such places. The book achieves its object and can be recommended to those for whom it is written. There must be many working in industry who would be glad to know that it has been published.

K. M. A. P.

\section{THE JOURNEY TO WORK}

By K. Liepmann, Ph.D.

(International Library of Sociology and Social Reconstruction. Kegan Paul, Trench, Trubner and Co. London. 1944. Pp. 204. 15s.)

'Travelling ....' states the Barlow Report (p. 91), ' can hardly fail to have adverse effects on health and to result in fatigue (and) loss of energy. . . . There can be little doubt, too, that these adverse effects on the workers are reflected in no small measure on their efficiency and output and in turn, on the employers' cost of production.' Industrial medical officers will agree with these words quoted by Dr. Liepmann, but will understand her comment that this statement is founded on a general impression and not on exact knowledge as there have been previously no special investigations published on the subject. There are certain benefits to the worker resulting from an ability to travel to his job, says the author; it "helps him in getting the right job, in retaining a suitable job, in combining two intermittent (seasonal) jobs and in changing over from declining to flourishing industries,' and in 'the prevention of frequent migration of individuals and families. The worker's family as a whole benefits from the varied employment of its members and domestic life is enriched by a variety of occupational interests among the family.' It is also true, however, as Mr. Carr Saunders says in his admirable preface, that " less attention is perhaps paid to the positive evils arising from daily travel. It is not merely that time is wasted, it is not just that so many hours are lost from the day. To many daily travel is a cause of nervous fatigue; the zest of a new day is worn off before it has begun. More than that, no faculty can be properly exercised while travelling in crowds, it is difficult to read, to observe, to concentrate or to contemplate with any profit. The necessity of passing so much time each day during which profitable activity is difficult or impossible encourages the habit of passing all leisure time in this way. The daily journey to work is one of the features of modern life making for depersonalisation and accounts in some degree for the inability of men nowadays to enjoy themselves in creative activity or, indeed, in any fashion which demands more than passive response.'

Valuable charts are given showing in scale maps the residential distribution of employees of representative London and Birmingham factories.

Turning to the wider problems surveyed in this book Dr. Liepmann deals at length with the present problems 
of and implications for town planning which have resulted from the lack of co-operation between housing and other authorities. In London, for example, workers have to travel from Becontree to the new factories on the Great West Road. The policy of open development of the suburbs-an endeavour to house the urban population in rural surroundings-is shown clearly to have resulted in the unwieldiness of large cities, the lack of a feeling of community such as would more easily arise in the recommended compactness of building, and in increasing the distance to be travelled each day. Many suggestions are made as to remedies, but one which commends itself is the suggestion that 'communal leisure facilities and decentralized services should be supplemented by making the residential districts areas of local government.' Another important requirement of this wider issue is to foster citizenship also at work places. Society cannot afford to neglect the work places as potential foci of common interest and local affinity. If accompanied by a proper organization of social and civic life,' Dr. Liepmann concludes, 'the severance of dwelling-place and work place (as is now increasingly seen) may well prove to be for the benefit of the urban population.'

The second half of the book contains the results of statistical inquiries and includes the U.S.A. and German industrial centres. The whole book is of significance to those concerned with transport, town planning and industrial health.

J. G. B.

\section{A STUDY OF VARIATIONS IN OUTPUT}

Emergency Report No. 5 of the Industrial Health Research Board

By S. Wyatt, D.Sc.

(Assisted by R. Marriott, B.Sc., W. M. Dawson, B.Sc., D. E. R. Hughes, and F. G. L. Stock)

(H.M. Stationery Office. 1944. Pp. 16. 4d.)

It is widely held that, for economic reasons alone, the working week should be reduced below 60-65 hours for men or 55-60 hour for women-the so-called maximum levels for manual work involving medium physical effort. So an investigation was planned to prove the truth of this belief.

At the end of 1942 the weekly hours of work were reduced in certain factories; these were selected for this study. Although the reduction varied in different factories it was thought that the change in hours of work might have a measurable effect on output. It was therefore interesting to find that the most striking feature of the output records was their variability. Although stable operations were chosen for measurement there was often considerable weekly fluctuation. The chief causes of this were changes in the type of design of production, mechanical defects or breakdowns, variations in quantity or quality, progressive improvements in the methods of work, changes in the lay-out of machines, and personal factors such as dissatisfaction with wages or friction between management and workers. These points are of interest to the future investigator, and show some of the real difficulties in carrying out a scientific study of a problem such as this.

Despite the presence of these interfering factors, however, the hourly output increased in 15 out of 21 groups during the period covered. The average increase for all the factory groups was $4 \cdot 1$ per cent. but in some it ranged from 11 to 21 per cent. This satisfactory feature of the results was due mainly to small but progressive improvements in methods and conditions of work, but in some groups it was accelerated by fairly large-scale measures of reorganization. Although the effects of shorter hours of work were, in most groups, mainly obscured by the presence of other factors there is reason to believe that the effects were favourable. Thus in three groups free from disturbing influences the period after the reduction of hours showed an increase in hourly output of 3.3-6.3 per cent. In most groups the shorter working week was appreciated by the workers, especially by women with family and home responsibilities. In some groups there was a slight decrease in absenteeism. In general the trend of output was upwards despite the shorter hours of work. A comparison of the amount of absence in the different factories showed, on an average, that it was appreciably higher among two groups of women employed on a 3-shift system than among 5 groups of women on a 2-shift system. There was also a tendency for absence among men and women on a 2-shift system to decrease as the weekly hours of work decreased. On the 2 -shift system there was little difference between hourly output during night and day work. On the 3-shift system output was likely to be highest on the afternoon shift and lowest on the morning shift.

The Board rightly states that it is unjustifiable to make dogmatic statements about the results obtained which, incidently, corroborate previous work by Sargant Florence and others. But the fact that the investigation has been carried out, and has clearly shown the type of difficulty that can and will arise in similar studies, is justification for starting it. A wide field for research is thus again opened up.

D. S.

OCCUPATION AND HEALTH. SPECIAL SUPPLEMENT-INDUSTRIAL HEALTH IN WAR TIME

(International Labour Office, Montreal. 1944. Pp. 39.)

The International Labour Office has recently published a Special Supplement to its Encyclopaedia of Hygiene, Pathology, and Social Welfare. This deals with many aspects of industrial health as it is affected by war-time conditions in Great Britain, the U.S.A., the U.S.S.R., France, Germany, and other countries. Employment of large numbers of persons with no previous experience of industry, the necessity for work at high pressure, 'black-out' regulations, and the relaxation of many rules controlling health and safety, together with the handling of many noxious substances-some of which are new and imperfectly understood-have combined with difficulties in housing, transportation, and food so as to lead to much illness and loss of efficiency. Study and research in these matters have engaged the attention of those countries concerned, but exchange of information has been hindered by security considerations-many war-time processes are secret-and by difficulties in holding conferences and publishing reports.

In view of these conditions the present Supplement is of particular value; it gives, in the small compass of 39 pages, a summary of the principal observations made during the past four years in the fields of industrial hygiene and toxicology. This includes dust diseases; poisoning by lead, magnesium, mercury, and other metals; carbon monoxide; explosives; solvents; rubber substitutes-synthetic rubber has been produced in large quantities in Germany, the U.S.A., and, since 1935, in the U.S.S.R.; chlorinated naphthalenes; radio-active substances; and notes on caisson disease, aviation hygiene, and skin affections. References to recent literature on these subjects are given. $\quad$ D. C. N. 